\title{
15 Minutes of Attention in Class: Variability of Heart Rate, Personality, Emotion and Chronotype
}

\author{
Ubaldo Enrique Rodríguez de Avila', Fabíola Rodrigues de França Campos² \\ ${ }^{1}$ Department of Psychology, Universidad del Magdalena, Santa Marta, Colombia \\ ${ }^{2}$ Department of Physiotherapy, Universidade Federal do Rio Grande do Norte, Natal, Brasil \\ Email: rodriguez.ubaldo@gmail.com, fabiolafcampos@gmail.com
}

How to cite this paper: de Avila, U. E. R., \& de França Campos, F. R. (2019). 15 Minutes of Attention in Class: Variability of Heart Rate, Personality, Emotion and Chronotype. Creative Education, 10, 2428-2447. https://doi.org/10.4236/ce.2019.1011172

Received: October 18, 2019

Accepted: November 15, 2019

Published: November 18, 2019

Copyright () 2019 by author(s) and Scientific Research Publishing Inc. This work is licensed under the Creative Commons Attribution International License (CC BY 4.0).

http://creativecommons.org/licenses/by/4.0/ (c) (i) Open Access

\begin{abstract}
Until today, almost all studies on Sustained Attention (SA) in the classroom were based on the time management by the teacher and its effect on student attention, but almost none report objective and conclusive data on physiological factors that intervene and modulate the student's AS during class; which led the pedagogical sciences to consider that AS depends almost exclusively on the teacher's methodology. In this study, an AS Detection System in the classroom was designed and validated based on Heart Rate Variability (HRV) and through a non-parametric analysis of time, frequency and entropy measures, in A sample of 30 subjects, it was shown that the physiological response that promotes AS in students is activated between the first 15 to 20 minutes of a conventional class. In addition, it was verified that the Positive Affection, the Tension and the Chronotype modulate the AS in the first minutes, in the middle and at the end of the classes, and that there is a significant difference in the 40th minute for the morning and evening groups.
\end{abstract}

\section{Keywords}

Attention, Heart Rate Variability, Personality, Emotion, Chronotype, Students

\section{Introduction}

In the educational demand of the Teaching/Learning processes there is a need for the attention to be continuous or sustained over a long period of time. However, attention as a central process of cognition (Herrera, Cid, Pinilla, Quezada, \& Santana, 2016; Nobre \& Kastner, 2014; Yoo, Rosenberg, Hsu, Zhang, Li, 
Scheinost, Constable, \& Chun, 2018) also has neural integration substrate (Rohr, Arora, Cho, Katlariwala, Dimond, Dewey, \& Bray, 2018) that influences learning (Onley, Risko, D'mello, \& Graesser, 2015) and is also determined by factors such as: physical characteristics of the stimuli, number of stimuli, rhythm, time and space of the stimulus (Cuervo \& Quijano, 2008).

\subsection{Attention and HRV Studies}

Several studies have sought to determine the time of AS in the classroom; for example, in the year 1976, Johnstone and Percival (cited by Bunce, Flens, \& Neiles, 2010) measured student attention during 90 different classes by observers external that recorded attention subjectively. A decrease in attention was observed in the first five minutes and another around 10 to 18 minutes.

Bunce et al. (2010) investigated the attention lapses reported by the same students during a class time of 50 minutes and found that students do not pay attention continuously for 10 to 20 minutes during a class. Instead, their attention alternates between being attentive and not attentive in shorter and shorter cycles along a 50-minute class segment. Additionally, Wilson and Korn (2007) reviewed several investigations with different types of attention measures: student annotations, observations of students during classes and self-reports of student attention and physiological measures. These authors state that student attention decreases approximately 10 to 15 minutes in class. They also reported that the research, on which the calculation of attention is based during classes, provides little support for the belief that student attention decreases after 10 to $15 \mathrm{mi}$ nutes, as most studies did not take into account the individual differences of the subject.

It should be noted that the physiological measure of SA, such as Heart Rate (HR) is considered an excitation indicator as a component of SA (Wilson \& Korn, 2007; Bradbury, 2016). Thus, the HR or variation of the time intervals measured between heartbeats (Capuana, Dwyan, Tays, Elmers, Witherspoon, \& Segalowitz, 2014; Shaffer \& Venner, 2013; Shaffer, McCraty, \& Zerr, 2014; Holzman \& Bridgett, 2017), is considered by the "Porges Polyvagal Perspective" (Porges, 1995, 2001, 2007) and the "Neurovisceral Integration Model" (Thayer \& Lane, 2000; Thayer, Hansen, Saus-Rose, \& Johnsen, 2009) as part of the pre-frontal cortical substrates of top-down self-regulation, influenced by the Autonomous Nervous System-ANS (subdivided into Parasympathetic Nervous System-PNS and Sympathetic Nervous System-SNS) (Cardinali, 2018; Holzman \& Bridgett, 2017), which influences the psychological (Capuana et al., 2014) and emotional processes (Appelhans \& Luecken, 2006). In this way, the activation of the SNS produces an increase in the HR and the PNS decreases the HR; This fluctuation is known as HR Variability-HRV (Fonfría, Poy, Segarra, López, Esteller, Ventura, Moltó et al., 2011) which at the same time makes it possible to measure SA objectively. Thus, the activity of the ANS plays a fundamental role in implicit learning (Forman-Alberti \& Benjamin-Hinnant, 2016), in cognition, 
in emotional and mainly in attention (Bermudez, Klerman, Czeisler, Cohen, Wyatt, \& Phillips, 2016; De Abreu, 2012; Ohyama et al., 2016; Serrano-Trejo, Leija-Alva, Aguilera-Sosa, \& Rodríguez-Choreño, 2012; Sanchis, Prat, \& Sitges, 2016; Graveline \& Wamsley, 2017; Itzek-Greulich, Randler, \& Vollmer, 2016; Luque-Casado, Perales, Cárdenas, \& Sanabria, 2016).

In a systematic review and meta-analysis (Robe, Dobrean, Crístea, Păsărelu, \& Predescu, 2019) they found a significant relationship between the Attention processes with the HRV. For their part, Griffiths, Quintana, Hermens, Spooner, Tsang, Clarke and Kohn (2017) conclude that the time and frequency measurements of the HRV offer important information about AS, emotion and behavior. The analysis of the HRV and its relationship with attention was also used by Chang and Huang (2012), who in a laboratory procedure, presented the participants with two types of tasks (low and high attention); The study concluded that both the demand for tasks regarding the operation of care processes result in changes in the HRV.

\subsection{Studies on Personality, Emotion and HRV}

At the same time, personality has been studied as a structural dimension of the psychology of the individual (Matthews, 2016; Linden, Dunkel, \& Petrides, 2016; Revelle, 2016) and emotions are understood as a set of events that arise at the level of psychological description constituted by neurobiological processes, with holistic empirical approach (Barrett, Mesquita, Ochsner, \& Gross, 2007; LeDoux, Phelps, \& Alberini, 2016; Purnamaningsih, 2017; LeDoux \& Brown, 2017) that are related to SA, perception, cognition and personality (Pessoa, 2018), which should be approached comprehensively (Cowen \& Keltner, 2017) in the interaction with the school context in which the student develops (Scott-Parker, 2017) and the way in which together with the Personality modulates attention (Mogg \& Bradley, 1999).

Today we know, for example, that there is interaction between negative affectivity and attention control (Lonigan \& Vasey, 2009). Therefore, an individual's ability to regulate emotion can modulate the extent to which attention is directed toward any stimulus or threat (Cisler \& Koster, 2010; Peers \& Lawrence, 2009) and unless attention control in highly anxious individuals, the processing of stimuli that are not threatening will be low (Ortega, Ramírez, Colmenero, \& García-Viedma, 2012) and although the existence of the emotion/attention relationship is clear (Pacheco-Unguetti, Acosta, Callejas, \& Lupiáñez, 2010), the same does not happen with the personality/attention relationship; hence the nature of that relationship needs to be defined in terms of objective measures. And the HRV is a biomarker that allows the integration of psychobiological processes precisely in natural contexts, as discussed in this study.

For example, in an exploratory study by Ramírez, Ortega and Reyes (2015) found that High Frequency HRV modulates the association between anxiety and SA control in situations involving neutral stimuli, and risk aversion in the taking 
of decisions. Similarly, the HRV of the High Frequency band was positively associated with the attentional control and was negatively associated with the risk aversion. It was also found that High Frequency HRV modulates the influence of anxiety both in the control of attention to neutral stimuli and in risk aversion in decision making, which is consistent with Mather and Thayer (2018), who found that individuals with high HRV tend to have better emotional well-being than those with low HRV.

Another study based on the reinforcement model, speed of learning in decision-making, modulated by positive and negative emotions, it was concluded that a low resting HRV shows a higher negative motivational value in response to negative images (Katahira et al., 2015), which somehow agrees with Quintana, Guastella, Outhred, Hickie and Kemp (2012) who verified association of the HRV with the recognition of emotions.

\subsection{Chronotype and HRV}

The Chronotype is the variation in the temporal organization of sleeping behavior, attributed to differences in circadian oscillation, sleep/wake cycle, related to psychological differences (Leocadio-Miguel et al., 2017; Randler \& Rahafar, 2017; Markarian, Warnke, \& Pickett, 2017; Roenneberg, Wirz-Justice, \& Merrow, 2003), is also considered as a key element in adolescent life (Touitou, Touitou, \& Reinberg, 2017) influencing health, academic performance (Borgio, Koga, Matynhak, \& Louzada, 2018; Escribano \& Díaz-Morales, 2016; Horzum, Önder, \& Beşoluk, 2014; Tonetti, Natale, \& Randler, 2015), in the consolidation of learning and memory (Araújo \& Almondes, 2012) and in the decision making among other multiple aspects (Ingram et al., 2016) and in Attention (Vollmer, Pötsch, \& Randler, 2013).

Roeser, Obergfell, Meule, Vögele, Schlarb and Kübler (2012) explored in an exploratory way the differences in the HRV and other cardiovascular measures in the Chronotypes of Morning and Evening students, at rest and under stress conditions at different times of the day. The findings of this study say that the Evening types have lower HRV than the Morning types and also that the increase in physiological arousal at night types could contribute to a greater vulnerability to psychological disorders (Roeser et al., 2012). In another study developed by Henelius, Sallinen, Huotilainen, Müller, Virkkala and Puolamäki (2014), they examined the use of spectral measures of the HRV to measure the sleepiness under chronic partial sleep restriction, concluding that the spectral power of the HRV reflects the SA in individuals exposed to partial sleep restriction (Henelius et al., 2014). On the other hand, Hasler, Allen, Sbarra, Bootzin and Bernert (2010) studied Morning and Evening individuals in a condition of depression and non-depression, in order to determine the relationship of Positive Affection with behavioral activation. The evidence provided by Hasler et al. (2010) reports that circadian rhythms can also be related to the Behavior Activation System and Positive Affection, but not with the Behavioral Inhibition Sys- 
tem or Negative Affection, and it is concluded that the morning activity it is associated with depression through indirect multi-step routes.

This study is based on two fundamental premises: 1) The HRV is the result of the interactions between the Autonomic Nervous System (ANS) and the heart's functioning mechanism; and the activity of the ANS is based on the balance of the SNS and SNP. 2) The activity of the ANS plays a fundamental role in SS, in emotional responses, in cognition and in learning. In this way, the objective of the study was: To examine the truth that the time of SA in students, in the classroom, can be measured from the HRV and modulated by personality, emotion and chronotype.

\section{Method}

\subsection{Participants}

In the validation study of the Attention Detection System based on the Variability of Hear Rate (ADS-HRV1) three male volunteers participated. Subsequently, in the next phase, through the method of approaching group interactions in ecologically natural environments (Dikker, Wan, Davidesco, Kaggen, Oostrik, McClintock, Poeppel et al., 2017) 30 participated: minimum age $=18$ years and maximum age $=45$ years $(M=20.5 \pm 6.951) ; 80 \%$ women $20 \%$ men; 23 first year physiotherapy students and 7 first year nursing students. The data was recorded during 1:30 p.m. during three class sessions. There was no intervention in the teacher's methodology. The methodology used was traditional with the use of Power Point. Students were connected to ADS-HRV1 five (5) minutes before class.

\subsection{Instruments and Techniques}

$A D S$ - $H R V 1$. It is designed for recording heartbeat in a natural environment, based on Arduino Technology. It is a platform for electronic prototypes of free hardware and single board, designed with a microcontroller by integrated input and output gate and standard programming language (Geddes, 2017; MacRoberts, 2015). The components of the ADS-HRV1 are: 1) Arduino: Open source electronic prototype based on flexible hardware and software. It was programmed using the "Arduino Programming Language" (based on Wiring) and the "Arduino Development Environment" (based on Processing). 2) Protoboard: Plate with contact matrix that allowed the construction of experimental circuits without welding. 3) Micro SD Memory Card Module: Device used to store information in numerical form. 4) Heart Rate Sensor: Amplified optical sensor that read the heartbeat. 5) 9 Volt Battery (9 V): Power source or ADS-HRV1 power supply.

Sixteen Personality Factor Questionnaire (16PF). Psychometric test validated for Brazil by Figueiredo de Barros and Menezes (1998) and Tomelin (2002). In this study two factors were used: Abstractedness (measurement of intelligence sensitive to the subject's schooling) and Tension (associated with floating anxie- 
ty, generalized frustrations, stress, anxiety manifested in sleep problems, agitation, impatience and irratibility). Abstractedness and Tension, as separate factors from the general instrument of the $16 \mathrm{PF}$, do not present statistical homocedasticity, therefore the report of mathematical reliability is not necessary.

Positive and Negative Affection Scale (EA) by Zanon, Roat, Cerentini and Hutz (2013). The EA Scale presented an internal consistency of 0.83 for Positive Affect and 0.77 for Negative Affect. It is composed of 20 items: 10 for Positive Affection and 10 for Negative Affect, organized by three categories: Low, Medium and High. This Scale conforms to the criteria of the Society for Affective Science that classifies and measures emotions in Positive and Negative (Meiselman, 2017).

Morningness-eveningness Questionnaire-MEQ of Horne and Ostberg (1976). Validated and standardized for Portuguese by Benedito-Silva et al. (1990), composed of 19 items. Scores vary between 16 and 86 points. Low scores indicate Evening type, high indicates Morning type and averages indicate Intermediate type. The distribution of the bimodality index (without type) is determined from the equation Bomodality Index $(\mathrm{BI})=(\Sigma \mathrm{A} 1 \times \Sigma \mathrm{A} 4)^{2}-(\Sigma \mathrm{A} 2 \times \Sigma \mathrm{A} 3)^{2}$ (Martynhak, Louzada, Pedrazzoli, \& Fontenele-Araujo, 2010).

\subsection{Data Processing}

The analysis of the heartbeat was made from values measured between consecutive RR Intervals, as established by the international standard of the European Society of Cardiology and the American Society of Stimulation and Electrophysiology (Shaffer et al., 2014). The observation window was 60 minutes in the time series, subdivided into 12 time segments of the 5-minute, processed with the "Kubios HVR Standard 3.1.0" software, which accurately identifies the RR Intervals and then performs the mathematical analyzes of the HHR in the domain of Time, of Frequency and Entropy (Tarvainen, Niskanen, Lipponen, Ranta-aho, \& Karjalainen, 2014; Yentes, Hunt, Schmid, Kaipust, McGrath, \& Stergiou, 2013). This is how the results of the HRV are divided:

1) Time Domain. a) RR intervals: Distance measured in milliseconds, between two successive R waves of the heartbeat. b) HR-Heart Rate: Number of heartbeats per minute. c) SDD-RR-Standard deviation of RR: Dispersion measurement that provides a quantification of the slow variations of the HRV. d) RMSDD-RR-Root Mean Square of the Successive Differences: Quantification of the abrupt variations of the HRV.

2) Frequency Domain. Treat the HRV as a variable frequency signal and the amounts are expressed in the distribution of the percentage (\%) of the power of the wave signal, related to the "rhythm" in which the variations occur: a) High Frequency Spectrum (\%HF): Power with a range of 0.15 to 0.4 hertz, reflects PNS activity. b) Low Frequency Spectrum (\%LF): With a range of 0.04 to 0.15 hertz; reflects the activity of the SNS and its emotional reactions (Shaffer et al., 2014). c) of the spectra LF/HF Ratio: Additional measure to assess the balance 
between sympathetic and parasympathetic activity of the heart. When the value of the LF/HF Ratio is low, it presupposes PNS dominance and when the value of the relationship is high, the predominance is of the SNS.

3) Nonlinear measurements. Entropy; parameters and statistics developed by Pincus (1991) based on chaos theory, which presents an explanatory model of the complexity of biological dynamics, related to the entropy of Kolmogorov, which offers a measure of the irregularity of a series of data. The algorithms are Approximate Entropy (ApEn) and Sample Entropy (SampEn), which are patterns to characterize the complexity and irregularity of the HRV signals.

\subsection{Information Processing}

The ADS-HRV1 validation was based on the paired system method: ADSHRV1/EKG Patron System. The EKG Patron System is the LabChart package, supplied by PowerLab, which displays the EKG data in real time. The RR Interval values were extracted, stored on the local PC using interfaces and software supplied by the manufacturer and the records were imported to the Excel 2007 version. Meanwhile, the heart rate records recorded by the ADS-HRV1 they were stored on the SD memory card, exported for the Excel 2007 version on a local PC. Long segments of the heartbeat recordings were used in 10 minute time. Subsequently, the system data were compared. The intra-class correlation (individual and average) and the Cronbrach Alpha were calculated exploratoryly. Confirmatory analysis of variance was performed. 12 paired records were analyzed: ADS-HRV $1_{1-12} /$ EKG Patron System.

Spearman's correlation index (R) was verified for data recorded by ADSHRV $1_{1-10} /$ EKG Patron System and Pearson's $\mathrm{R}$ index for records of ADS$\mathrm{HRV}_{11-12} /$ EKG Patron System. In the cross correlation a highly significant $\mathrm{R}$ index was verified for all systems $(\mathrm{R}=0.599$ to $\mathrm{R}=0.98 ; p<0.01)$. Individual Cross Correlation (ICC), intraclass cross correlation (InCC) and Cronbach's Alpha ( $\alpha$ ), showed a good fit $(\mathrm{ICC}=0.43$ to $\mathrm{ICC}=0.99$; $\mathrm{InCC}=0.69$ to $\mathrm{InCC}=$ $0.99 ; \alpha=0.61$ to $\alpha=0.99 ; p<0.01$.

Confirmatory analysis was made from Analysis of Variance with the Fisher-Snedecor statistic (f) for the ADS-HRV1 $1_{1-10} /$ EKG Patron System and the $\mathrm{t}$-Student statistic $(\mathrm{t})$ and for the ADS-HRV $1_{11-12} / \mathrm{EKG}$ Patron System. The result was the validity of the systems $[\mathrm{f}=1.86(p<0.05)$ to $\mathrm{f}=33.37(p<0.05) ; \mathrm{t}=2.92$ $(p<0.05)$ and $\mathrm{t}=28.41(p<0.05)]$. It is concluded that there is no significant variance among the twelve (12) ADS-HRV1.

The statistical method used for the next phase is Non-Parametric Inference with Analysis of Variance from the Friedman test in the time series of the HRV and the adjusted significance ( $p$-Adj) between the segments of the time series in each parameter of the HRV. The Global Median (GM) and the estimated vector distance (linear fit or $\mathrm{R}^{2}$ ) are also calculated and displayed. In the case of the Psychological variables, Spearman's correlation was performed, beyond the descriptive statistics and to verify the modulation of the psychological variables 
and the Chronotype the SA from the HRV, the Chi-square $\left(\chi^{2}\right)$ of Kruskal-Wallis was used and a significance of $p<0.05$ was established; In addition, $p$-Adj was verified for categorical data.

The following software packages were used: 1) Sketch_may24a|Arduino1.8.9 (for Windows): Free software used to mount the ADS-HRV1 code. 2) Kubios HVR Standard 3.1.0. Free software used to identify the RR Intervals in the time series. 3) IBM Statistics SPSS-20. 4) Microsoft Excel for Windows.

\section{Results}

The lowest number of heart pulses was 5338 and the highest was 8678 . The overall average was 6444 . The GM of Interval RR was $683.3 \pm 61.95$. Table 1 shows

Table 1. Descriptive statistics of the parameters of the VFC in the 60-minute time series.

\begin{tabular}{|c|c|c|c|c|c|c|c|c|c|c|}
\hline \multirow{2}{*}{ Time } & \multirow{2}{*}{ Dispersion } & \multicolumn{4}{|c|}{ Time Domain } & \multicolumn{3}{|c|}{ Frequency Domain } & \multicolumn{2}{|c|}{ Entropy } \\
\hline & & $\mathrm{RR}$ & FC & SDD-RR & RMSDD-RR & $\% \mathrm{LF}$ & $\% \mathrm{HF}$ & $\mathrm{LF} / \mathrm{HF}$ & ApEn & SampEn \\
\hline \multirow{2}{*}{5} & Median & 702 & 85.5 & 42.5 & 45.75 & 58.33 & 41.53 & 2.07 & 1 & 1.97 \\
\hline & \pm & 86.48 & 11.83 & 10.9 & 11.32 & 15.88 & 15.8 & 2.08 & 0 & 0.18 \\
\hline \multirow{2}{*}{10} & Median & 677 & 89 & 37.65 & 39.2 & 56.47 & 43.67 & 1.83 & 1 & 2 \\
\hline & \pm & 85.03 & 11.74 & 7.38 & 7.89 & 13.21 & 12.56 & 1.7 & 0 & 0 \\
\hline \multirow{2}{*}{15} & Median & 701.5 & 85.5 & 38.1 & 37.7 & 52.43 & 47.73 & 1.4 & 1 & 1.97 \\
\hline & \pm & 95.16 & 14.59 & 9.37 & 19.67 & 12.35 & 12.5 & 0.89 & 0 & 0.18 \\
\hline \multirow{2}{*}{20} & Median & 684 & 88 & 38.75 & 36.45 & 58.9 & 41.03 & 2.03 & 1 & 1.93 \\
\hline & \pm & 82.79 & 11.65 & 12.28 & 13.21 & 15.73 & 15.71 & 1.77 & 0 & 0.25 \\
\hline \multirow{2}{*}{25} & Median & 702 & 85.5 & 41.35 & 40.45 & 59.2 & 40.67 & 1.97 & 1 & 1.9 \\
\hline & \pm & 93.96 & 13.5 & 11.44 & 13.04 & 16.68 & 16.53 & 1.4 & 0 & 0.31 \\
\hline \multirow{2}{*}{30} & Median & 709 & 84.5 & 43.45 & 38.8 & 62.07 & 37.8 & 2.23 & 1 & 2 \\
\hline & \pm & 102.17 & 14.57 & 10.84 & 13.31 & 13.72 & 13.68 & 1.65 & 0 & 0 \\
\hline \multirow{2}{*}{35} & Median & 713.5 & 84 & 40.8 & 39.75 & 62.3 & 37.67 & 2.67 & 1 & 1.97 \\
\hline & \pm & 92.59 & 13.14 & 10.69 & 11.42 & 16.36 & 16.39 & 2.94 & 0 & 0.18 \\
\hline \multirow{2}{*}{40} & Median & 691.5 & 87 & 43.4 & 39.6 & 62.37 & 37.47 & 2.1 & 1.03 & 1.9 \\
\hline & \pm & 88.55 & 12.29 & 12.54 & 12.95 & 13.59 & 13.44 & 1.45 & 0.18 & 0.31 \\
\hline \multirow{2}{*}{45} & Median & 705 & 85 & 41.15 & 36 & 64.3 & 35.5 & 3.03 & 1 & 1.83 \\
\hline & \pm & 76.43 & 10.16 & 13.13 & 12.77 & 12.9 & 12.81 & 3.15 & 0 & 0.38 \\
\hline \multirow{2}{*}{50} & Median & 722.5 & 83 & 46.5 & 39.2 & 66.7 & 33.2 & 3.37 & 1 & 1.87 \\
\hline & \pm & 83.16 & 10.98 & 14.15 & 16.07 & 15.08 & 15.08 & 3.85 & 0 & 0.35 \\
\hline \multirow{2}{*}{55} & Median & 720.5 & 83 & 39.35 & 37.15 & 61.73 & 38.17 & 2.67 & 1 & 1.97 \\
\hline & \pm & 88.14 & 11.73 & 12.52 & 15.89 & 17.22 & 17.2 & 2.9 & 0 & 0.18 \\
\hline \multirow{2}{*}{60} & Median & 725.5 & 82.5 & 40.25 & 37.8 & 60.1 & 39.83 & 1.97 & 1 & 1.9 \\
\hline & \pm & 92.93 & 12.5 & 12.53 & 15.23 & 15.8 & 15.73 & 1.22 & 0 & 0.31 \\
\hline
\end{tabular}


the descriptive statistics of the raw data in the time series.

In the Time Domain of the HRV, the analysis of the variance of RR Intervals, there was a significant difference in the general time series $[\mathrm{F}=58.38(11) ; p<$ 0.05]. Friedman's $p$-Adj revealed a difference between the 10/50 time segments $[\mathrm{F}=-3.883 ; p=0.002], 10 / 55[\mathrm{~F}=-3.467 ; p=0.013], 10 / 60[\mathrm{~F}=-4 ; p=0.001]$, $15 / 50[\mathrm{~F}=-4.567 ; p<0.01], 15 / 55[\mathrm{~F}=-4.15 ; p=0.001], 15 / 60[\mathrm{~F}=-4.683 ; p<$ $0.01], 20 / 50[\mathrm{~F}=-3.633 ; p=0.006], 20 / 55[\mathrm{~F}=-3.217 ; p=0.036]$ and $20 / 60[\mathrm{~F}=$ -3.75; $p=0.004$ ] (Figure 1(A-1)). In the same way, the HR parameter showed a significant difference in the time series $[\mathrm{F}=57.845(11) ; p<0.05]$ and $p$-Adj revealed difference between the 10/50 time segments $[\mathrm{F}=3.6 ; p=0.007], 10 / 55[\mathrm{~F}$ $=3.383 ; p=0.018], 10 / 60[\mathrm{~F}=3.393 ; p=0.002], 15 / 50[\mathrm{~F}=4.4 ; p<0.01], 15 / 60$ $[\mathrm{F}=4.733 ; p<0.01], 20 / 50[\mathrm{~F}=3.217 ; p=0.036], 20 / 55[\mathrm{~F}=4.183 ; p<0.01]$, $20 / 60[\mathrm{~F}=3.55 ; p=0.009]$ and $35 / 60[\mathrm{~F}=3.282 ; p=0.028]$ (Figure 1(A-2)). In the SDD-RR parameter, a significant difference in the time series was verified $[\mathrm{F}=$ 20.515 (11); $p=0.039$ ], however, $p$-Adj showed no significant difference between the associated temporal segments (Figure 1(A-3)). In the RMSDD-RR parameter, significant variance was verified in the time series $[\mathrm{F}=35.391(11) ; p<0.05]$ and with the $p$-Adj there was a significant difference between the $5 / 20$ time segments $[\mathrm{F}=3.617 ; p=0.007], 5 / 30[\mathrm{~F}=3.733 ; p=0.004], 5 / 35[\mathrm{~F}=4.8 ; p<0.01], 5 / 45[\mathrm{~F}$ $=3.567 ; p=0.008]$. There are 4 pairs of temporal segments (Figure $1(\mathrm{~A}-4)$ ).

Regarding the Frequency Domain of the VFC, the analysis of variance showed a significant difference in the time series for the \%LF parameter $[\mathrm{F}=30.668(11)$; $p=0.001]$ and $p$-Adj revealed difference between the 10/50 time segments $[\mathrm{F}=$ $-3.533 ; p=0.01]$ and $15 / 50[\mathrm{~F}=-4.367 ; p<0.01]$ (Figure 1(B-5)). In the same way, a significant difference was found in the variance of the time series for the \%HF parameter $[\mathrm{F}=32.520(11) ; p=0.001]$ and $p$-Adj revealed difference between the 10/50 time segments $[\mathrm{F}=3.7 ; p=0.005]$ and $15 / 50[\mathrm{~F}=4.433 ; p<$ 0.01] (Figure $2(B-5)$ ). For the LF/HF Ratio parameter, significant variation was verified in the time series $[\mathrm{F}=31.286(11) ; p=0.001]$ and $p$-Adj revealed a difference between 15/50 time segments [ $\mathrm{F}=-3.317 ; p=0.02]$ (Figure $1(\mathrm{~B}-6)$ ).

The non-linear results of the VFC (Entropy), the analysis of variance showed that there is no significant difference in the time series for the ApEn parameter $[\mathrm{F}=11(11) ; p=0.443]$. On the contrary, a significant difference was found in the variance of the time series for the SampEn parameter $[\mathrm{F}=23.692(11) ; p=$ $0.014]$. However, no significant difference was found between the time segments of the series using $p$-Adj (Figure 1(C-7)).

Regarding the results of the Psychological data, $100 \%$ of the subjects had a score in the intelligence profile test, that is, they are defined by abstract thinking. As for tension, $3 \%$ have low voltage, $17 \%$ control the tension while $80 \%$ show high tension. Regarding Emotion, 17\% of the subjects present a medium level in the Positive Affect score, while 83\% show a high level in this emotion. Likewise, only 3\% have a low level in Negative Affect, $47 \%$ a medium level and the remaining 50\% a high level in Negative Affect. The Chronotype, it was found that 

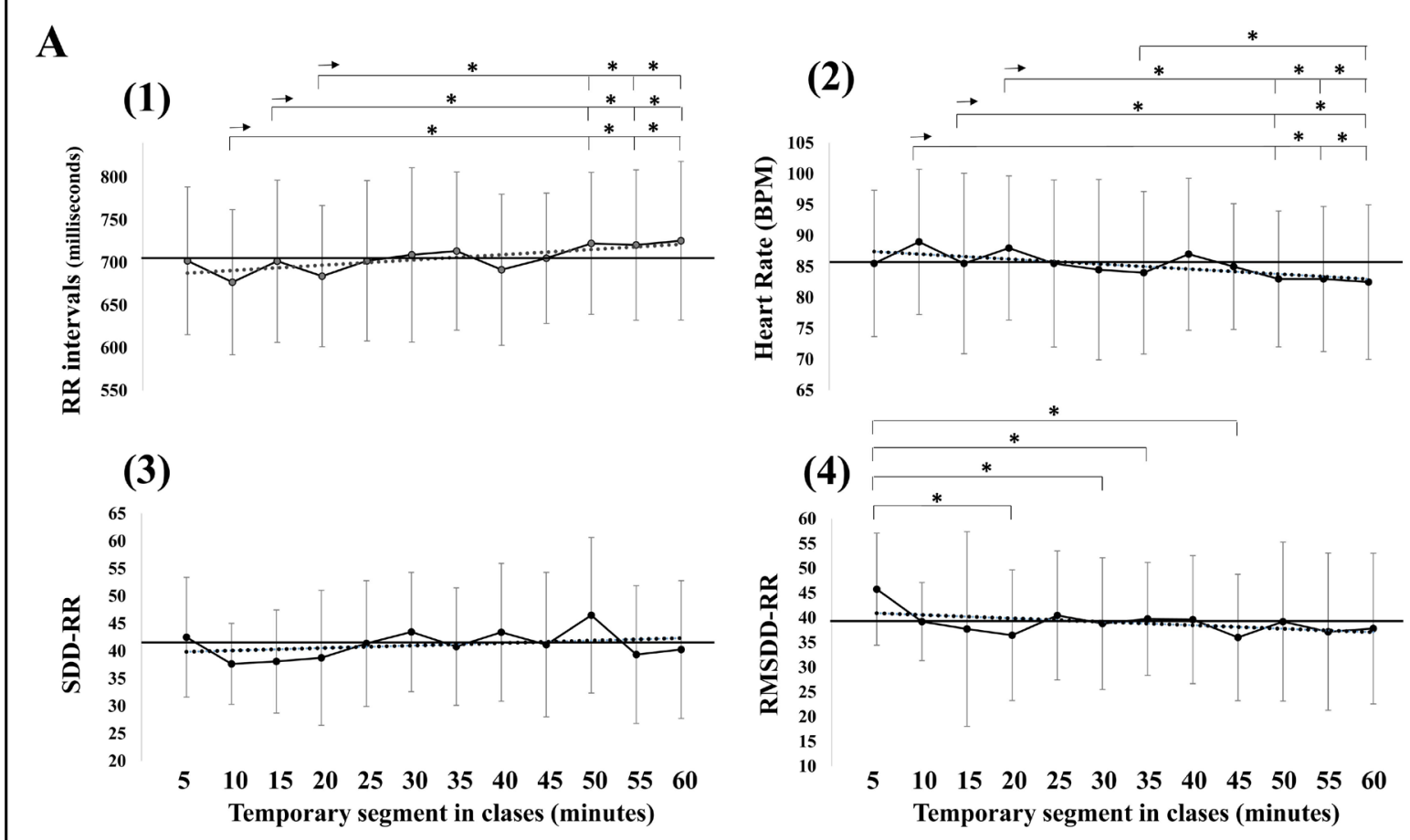

B

(5)

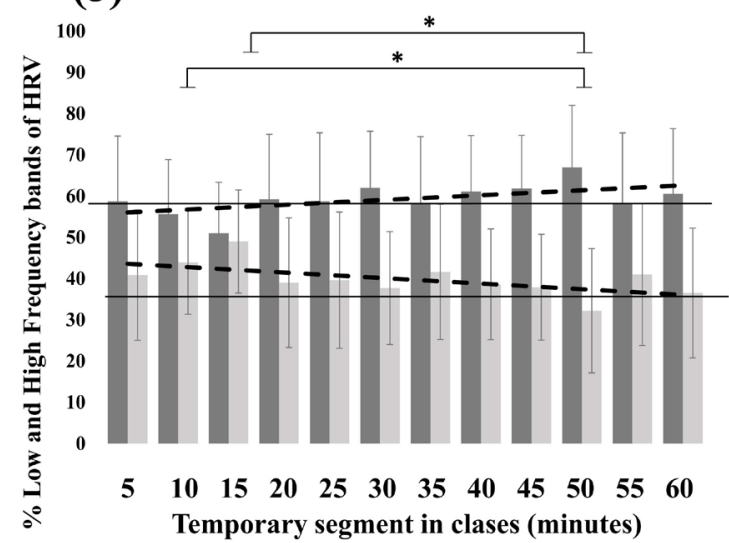

(6)

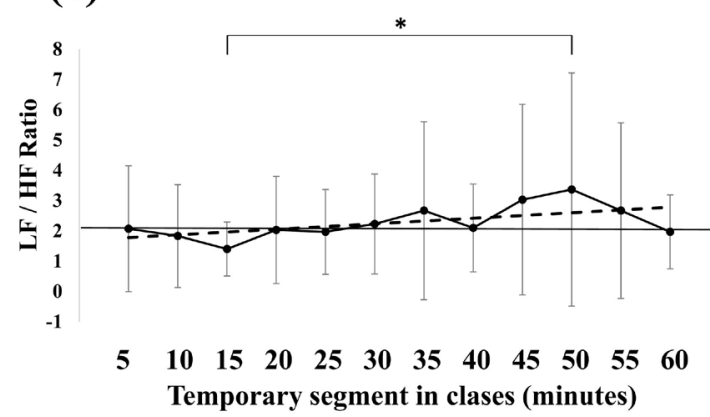

(7)
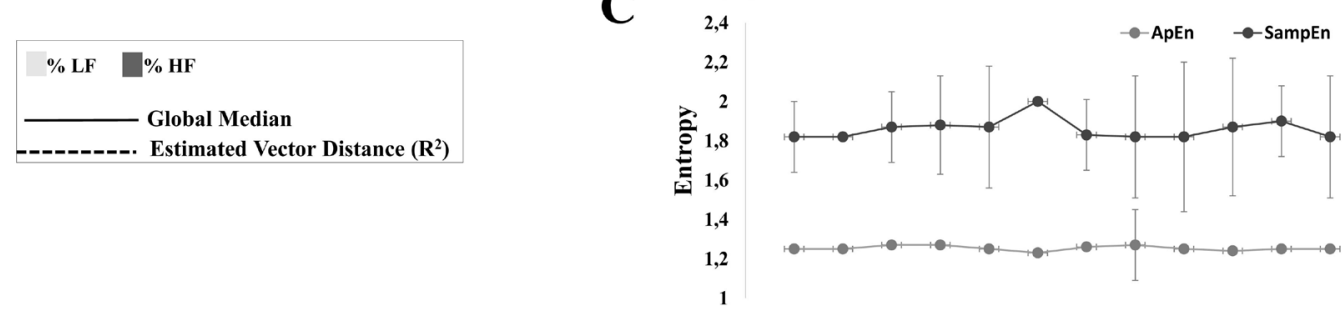

$\begin{array}{llllllllllll}5 & 10 & 15 & 20 & 25 & 30 & 35 & 40 & 45 & 50 & 55 & 60\end{array}$ Temporary segment in clases (minutes)

Figure 1. Variation in the time series of the parameters of the HRV. The horizontal line corresponds to the time series analyzed in segments of 5 minutes. *Significant variation $p<0.05$. $(\rightarrow)$ indicates the starting address of the comparison between a time segment and others. (A) Time Domain: (1) RR Interval $\left(\mathrm{R}^{2}=0.54\right.$; $\left.\mathrm{GM}=704.5\right)$. (2) HR $\left(\mathrm{R}^{2}=0.52\right.$; $\left.\mathrm{GM}=85.2\right)$. (3) $\mathrm{SDD}-\mathrm{RR}\left(\mathrm{R}^{2}=\right.$ $0.1 ; \mathrm{GM}=41.1)$. (4) RMSDD-RR $\left(\mathrm{R}^{2}=0.24 ; \mathrm{GM}=38.9\right)$. (B) Frequency Domain: (5) \%LF and \%HF [\%LF $\left(\mathrm{R}^{2}=0.31 ; \mathrm{GM}=\right.$ 59.3), \%HF $\left(\mathrm{R}^{2}=0.35 ; \mathrm{GM}=38.9\right)$. (6) LF/HF Ratio $\left(\mathrm{R}^{2}=0.36\right.$; $\left.\mathrm{GM}=2\right)$. (C) Non-linear measures (Entropy): (7) ApEn and Sa$\mathrm{mEn}: \mathrm{R}^{2}$ and $\mathrm{GM}$ are not significant. 
$17 \%$ have a Vespertinity condition, 70\% have Intermediate chronotype features, $7 \%$ have Morning chronotype characteristics and the other 7\% Bimodality.

Through Spearman's bivariate correlation, six (6) significant correlations were identified (Figure 2). No significant correlations were found between the different behavioral variables and the variables of the subject Sex and Age.

Verifying how SA is modulated by personality, emotion and the Chronotype, we have the following: In the Time Domain of the HRV, no significant difference was found in any time segment for any of the parameters when compared with the Psychological variables. In the Frequency Domain, a significant difference was found for Chronotype, at minute 40 for $\% \mathrm{HF}\left[\chi^{2}=9.853(3) ; p=0.020\right]$ and there was also a significant difference between the Evening and Morning groups, extracted from the Kruskal-Wallis test $[\mathrm{H}=-20.1(\mathrm{DV}=-2.73) ; p=$ 0.038] (Figure 3(A2)). Similarly, a significant difference for Chronotype was found in the parameter LH/HF Ratio $\left[\chi^{2}=8.509\right.$ (3); $\left.p=0.037\right]$ (Figure 3(A) and Figure $3(B)$ ), however the analysis of the intragroup variance showed no difference between the Chronotype categories.

To Entropy, significant difference was found for Tension, Positive Affect and Chronotype at different minutes, as follows: Tension: Minute $40\left[\chi^{2}=9.309(2)\right.$; $p=0.01]$, Minute $50\left[\chi^{2}=7.041(2) ; p=0.03\right]$, Minute $60\left[\chi^{2}=9.309(2) ; p=\right.$ 0.01 ] (Figure 3(C1)). Positive Affect: Minute $5\left[\chi^{2}=5(1) ; p=0.025\right]$, Minute 15 $\left[\chi^{2}=5(1) ; p=0.025\right]$, Minute $35\left[\chi^{2}=5(1) ; p=0.025\right]$, Minute $55\left[\chi^{2}=5(1) ; p\right.$ $=0.025]$ (Figure 3(C2)). Chronotype: Minute $15\left[\chi^{2}=14(3) ; p=0.003\right]$, Minute $20\left[\chi^{2}=8.804(3) ; p=0.032\right]$, Minute $35\left[\chi^{2}=14(3) ; p=0.003\right]$ and Minute 60 $\left[\chi^{2}=14(3) ; p=0.003\right]$ (Figure 3(C3)). No significant variance was found in any time segment for the ApEn and SampEn parameters of the HRV when compared

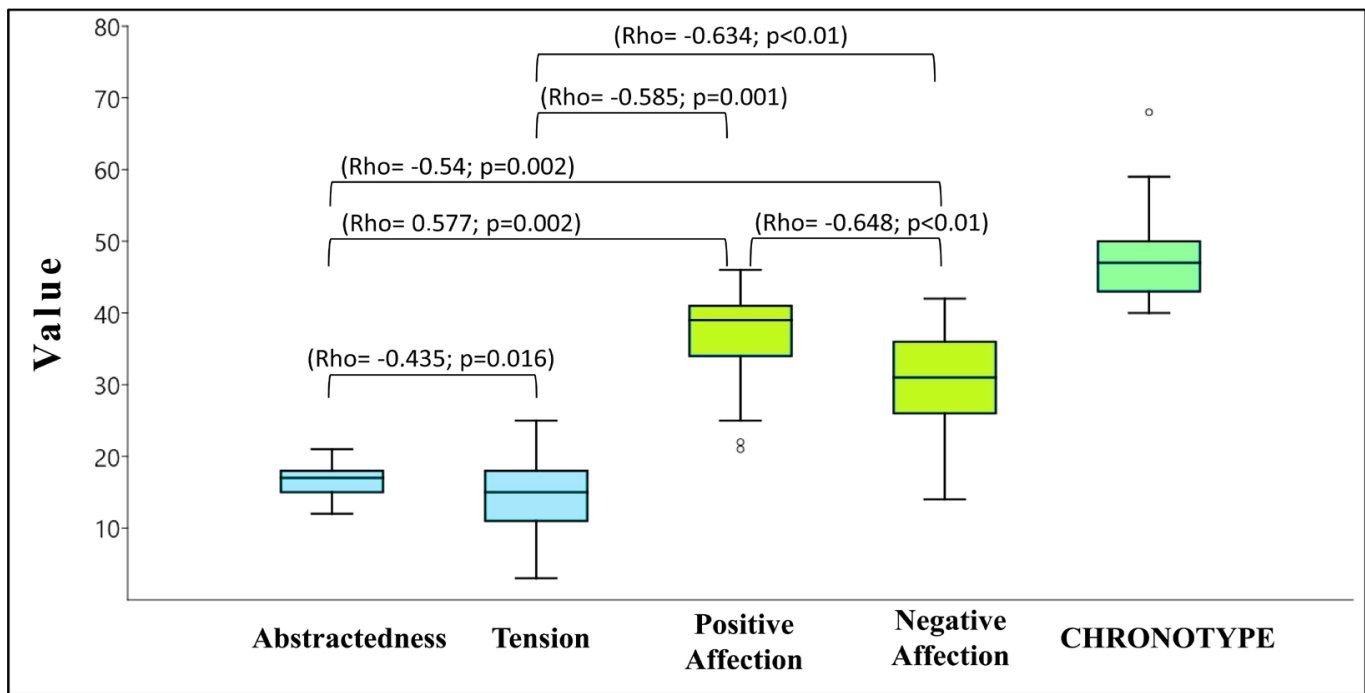

Figure 2. Cash diagram and significant correlations of the psychological and chronotype variables. Rho: Spearman correlation. Abstractedness: min. value $=12$, max. value $=21(\mathrm{M}=16.5 \pm 2.3)$. Tension: $\min$. value $=3$, max. value $=25(\mathrm{M}=14.5 \pm 5.4)$. Positive Affection: min. value $=21$, max. value $=46(\mathrm{M}=38.5$ $\pm 7)$. Negative Affection: min. value $=14$, max. value $=42(\mathrm{M}=30.5 \pm 6.5)$. Chronotype: min. value $=25$, max. value $=80(\mathrm{M}=56.5 \pm 11)$. 


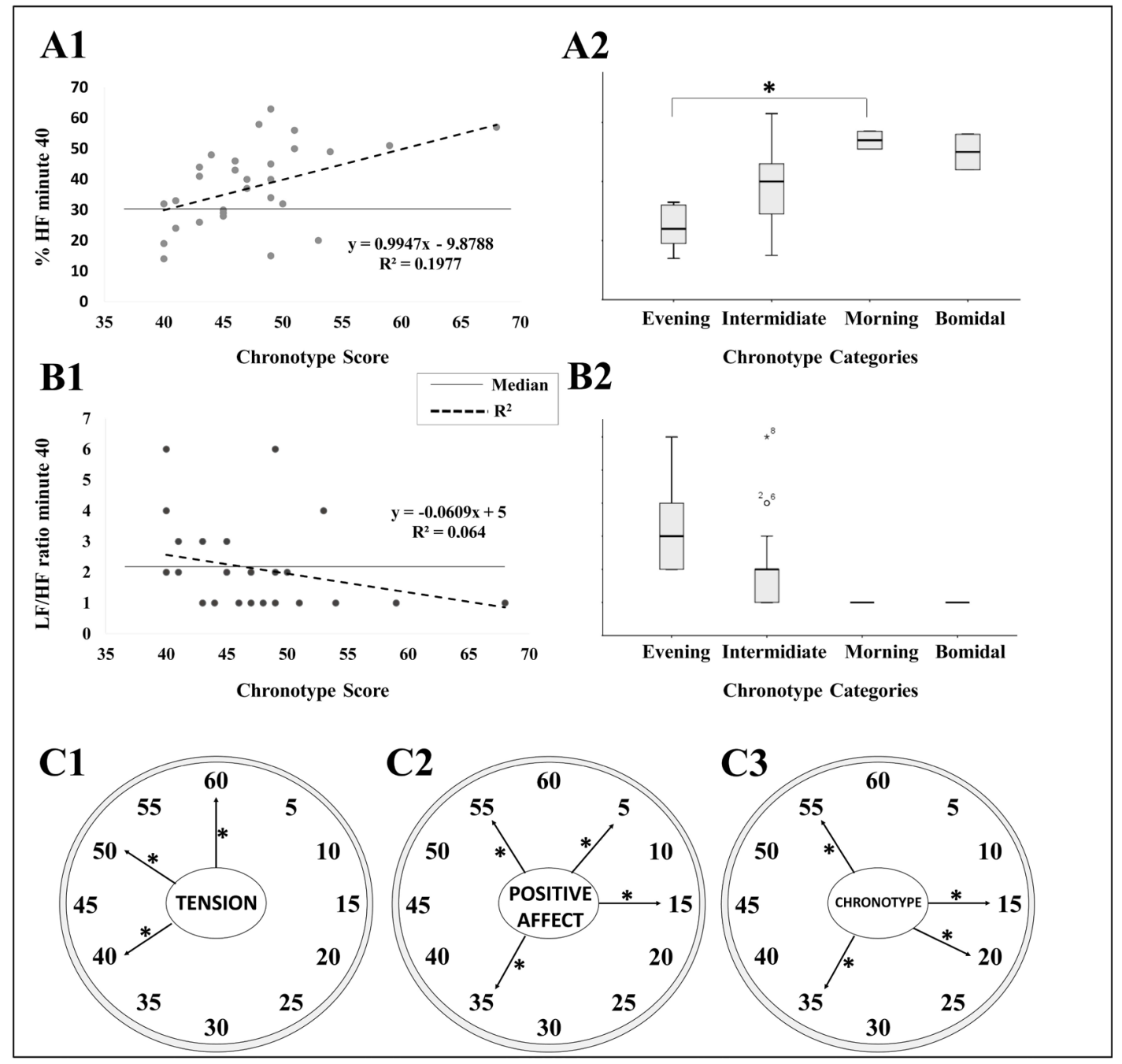

Figure 3. Mutation of attention from the domain of frequency and entropy of the HRV. A. Distribution of the Chronotype score (horizontal line) and \%HF of 40 minute time segment (vertical line). (A1) Dispersion of the Chronotype values with linear and median adjustment. (A2) Cash diagram of the Chronotype categories in relation to \%HF in 40 minute time segment. ${ }^{*}$ Significant difference of Kruskal-Wallis, $p$-Adj > 0.05 between Evening and Morning. (B) Distribution of Chronotype score (horizontal line) versus LF/HF Ratio in time segment minute 40 (vertical line). (B1) Dispersion of Chronotype values with linear and median adjustment. (B2) Cash diagram of the Chronotype categories versus LF/HF Ratio in 40 minute time segment. (C) Analysis of the Kruskal-Wallis Variance for SampEn and Psychological variables. ${ }^{\star}$ Significant variation in the time series for Tension (C1), Positive Affect (C2) and Chronotype (C3).

with categorical Psychological variables.

\section{Discussion}

In the present study, a progressive decrease of the HR calculated in $7.3 \%$ reduction (from the $10^{\text {th }}$ minute to the $60^{\text {th }}$ minute of the class) is verified, which corroborated for Bligh in a year 200 (Bradbury, 2016) who describes that the HR constantly decreased by approximately $14 \%$ from the beginning to the end of the class, with a moderate increase towards the end of the class. The progressive decrease in HR indicates a predominance of PNS, which suggests that the subject 
loses the alertness and neurocognitive excitability necessary to keep the SA in class.

In the present study, the time measurements of the VFC, mainly the values offered by Intervalos RR and of the FC, are susceptible to be able to determine the significant differences between the time segments by non-parametric methods. For example, significant differences were identified between three initial time segments (10, 15 and 20) and the last three time segments (50, 55 and 60). There was also a significant difference between half of the class and the final one, based on the RMSDD-RR parameter; which suggests that the individual differences of the subject may be modulating the HRV and therefore the SA in the students.

The HRV frequency measurements (\%LF, \%HF and LF/HF Ratio) provide confirmatory data of the significant differences between initial and final time segments, that is, between the first 15 minutes of the class and the last $15 \mathrm{mi}$ nutes. In addition, time segments 15 and 50 respectively, were more susceptible to identify significant variations. This demonstrates that the HRV systematically decreases throughout a class with classical methodology in a duration of $60 \mathrm{mi}$ nutes, and that the students pay more attention in the first 15 minutes, as opposed to the conclusions of Johnstone and Percival in a year 1976 (Bunce et al., 2010), which observed, subjectively, a decrease in attention in the first five minutes and another around 10 to 18 minutes.

The data found in the present study suggest that the general characteristic of the students' personality (Abstractedness and Tension), are configured through skills that are acquired through extended practice over time, as proposed by Matthews (2016). In turn, the reasoning was inversely correlated with Tension and Positive Affect, which means that as the rationale score increases, stress levels and negative affect tend to be lower; that is: Abstractedness is a protective or modulating factor of emotions. This is further corroborated by the positive correlation found between reasoning and Positive Affect.

Positive Affect is positively associated with Abstractedness and inversely with Negative Affect and with Tension. This suggests that positive emotions have a preponderance as a protective factor of multiple social situations, in accordance with the evidence of Rico, Alzate and Sabucedo (2017) and with the proposal of Scott-Parker (2017) who propose that the emotions experienced as internal subjective states, can be outsourced through behaviors in response to relatively stable personality characteristics (trait), less stable factors (status) or in response to context-specific activators (teacher/peer interaction). Current evidence suggests that emotional processing is intertwined with perception, cognition and personality (Pessoa, 2018). This was identified in the present study.

No significant relationships were found between the Chronotype factor with the other psychological variables. Thus, the present data do not support the findings of Hasler et al. (2010) who reported that the chronotype is related to Positive Affect. 
Evidence was found that Tension, Positive Affect and Chronotype modulate the SA in the first minutes, midway through and at the end of classes. What supports the results of studies that demonstrate the relationship between low attention control and high negative emotion (Ortega et al., 2012), or between the interaction between negative affectivity and attention control (Lonigan \& Vasey, 2009), as well as the data that suggest emotion as an SA modulator (Cisler \& Koster, 2010; Peers \& Lawrence, 2009).

Although some studies suggest that the frequency domains of the HRV (mainly of the HF band) modulates the association between anxiety and SA (Ramírez et al., 2015), no evidence was found in the present study.

Another important result was to identify from the measures of the frequency of the HRV, from the domain of \%HF, a significant difference between evening and morning in the 40th minute, supporting the studies by Roeser et al. (2012); what seems to be that the increase in physiological arousal in nocturnal types could contribute to a greater vulnerability to psychological disorders (Roeser et al., 2012). This study reveals that the morning show a greater activation of the SNS at the end of the class, which allows a physiological condition for the AS, compared to the evening, which in this time segment has a predominance of PNS. Thus, this study demonstrates that the measures of the frequency of the HRV reflect the SA and help identify how the Chronotype modulates it, as suggested by Henelius et al. (2014) based on a search in all frequency bands of HRV.

This study represents an important input for the methodological processes of teaching activity, by demonstrating that AS decreases over time, after the first 15 minutes of pedagogical activity. And in addition to this, individual factors of the psychological structure of the students modulate the SA in the classroom. However, more studies are necessary to demonstrate whether various teaching methods are involved or not in the SA during classes. Likewise, the notion that long classes should be discarded because students only have an attention period of 10 to 15 minutes is an accelerated conclusion. What is suggested is to combine expository and dynamic methods to modify physiological alert activations in students; or present relevant content to students in no more than 15 minutes.

Similarly, you should inquire more about the influence of the Morning and Evening chronotypes on the HRV, and how they modulate the SA during different hours of classes in the day. And finally, the analysis of the Entropy of the HRV is a sensitive method to identify significant differences between the psychological structure and the HRV; therefore, it is suggested to conduct more research and deepen these methods of analysis to understand more psychobiological associations in natural and experimental contexts.

\section{Disclaimer}

The views expressed in this paper are solely those of the authors and do not necessarily reflect the views of any company or organization. 


\section{Ethical Aspects}

This study was carried out with the support of the Coordination of Higher Level Personnel Improvement-Brazil (CAPES) - financing code 001. Approved by the ethics committee of the UFRN (Appear Consubstanciado do CEP Number: $2,683,191$.

\section{Conflicts of Interest}

The authors declare no conflicts of interest regarding the publication of this paper.

\section{References}

Appelhans, B. M., \& Luecken, L. J. (2006). Heart Variability as an Index of Regulated Emotional Responding. Review of General Psychology, 10, 229-240.

https://doi.org/10.1037/1089-2680.10.3.229

Araújo, D. F., \& Almondes, K. M. (2012). Qualidade de Sono e sua Relação com o Rendimento Acadêmico em Estudantes Universitários de Turnos Distintos. PSICO, 43, 350-359.

http://revistaseletronicas.pucrs.br/ojs/index.php/revistapsico/article/viewArticle/9369

Barrett, L. F., Mesquita, B., Ochsner, K. N., \& Gross, J. J. (2007). The Experience of Emotion. Annual Review of Psychology, 58, 373-403. https://doi.org/10.1146/annurev.psych.58.110405.085709

Benedito-Silva, A. A., Menna-Barreto, L., Marques, N., \& Tenreiro, S. (1990). A Self-Assessment Questionnaire for the Determination of Morningness-Eveningness Types in Brazil. Progress in Clinical and Biological Research, 341B, 89-98. https://www.ncbi.nlm.nih.gov/pubmed/2217379

Bermudez, E., Klerman, E., Czeisler, C., Cohen, D., Wyatt, J., \& Phillips, A. (2016). Prediction of Vigilant Attention and Cognitive Performance Using Self-Reported Alertness, Circadian Phase, Hours since Awakening, and Accumulated Sleep Loss. PLoS ONE, 11, e0151770. https://doi.org/10.1371/journal.pone.0151770

Borgio, J. G. F., Koga, C. M. T., Matynhak, B., \& Louzada, F. (2018). Impairment of Sleep Quality and Quality of Life in Bimodal Chronotype Individuals. Chronobiology International, 35, 1525-6073. https://doi.org/10.1080/07420528.2018.1464463

Bradbury, N. A. (2016). Attention Span during Lectures: 8 Seconds, 10 Minutes, or More? Advances in Physiology Education, 40, 509-513. https://doi.org/10.1152/advan.00109.2016

Bunce, D., Flens, E., \& Neiles, K. (2010). How Long Can Students Pay Attention in Class? A Study of Student Attention Decline Using Clickers. Journal of Chemical Education, 87, 1438-1443. https://doi.org/10.1021/ed100409p

Capuana, L. J., Dwyan, J., Tays, W. J., Elmers, J. L., Witherspoon, R., \& Segalowitz, S. (2014). Factors Influencing the Role of Cardiac Autonomic Regulation in the Service of Cognitive Control. Biological Psychology, 102, 88-97. https://doi.org/10.1016/j.biopsycho.2014.07.015

Cardinali, D. (2018). Autonomic Nervous System. Basic and Clinical Aspects. Buenos Aires: Springer International Publishing. https://doi.org/10.1007/978-3-319-57571-1

Chang, Y. C., \& Huang, S. L. (2012). The Influence of Attention Levels on Psychophysiological Responses. International Journal of Psychophysiology, 86, 39-47. 
https://doi.org/10.1016/j.ijpsycho.2012.09.001

Cisler, J., \& Koster, E. (2010). Mechanisms of Attentional Biases towards Threat in Anxiety Disorders: An Integrative Review. Clinical Psychology Review, 30, 203-216. https://doi.org/10.1016/j.cpr.2009.11.003

Cowen, A., \& Keltner, D. (2017). Self-Report Captures 27 Distinct Categories of Emotion Bridged by Continuous Gradients. Proceedings of the National Academy of Sciences of the United States of America, 114, E7900-E7909. https://doi.org/10.1073/pnas.1702247114

Cuervo, M., \& Quijano, M. (2008). Las alteraciones de la atención y su rehabilitación en trauma craneoencefálico. Revista pensamiento psicológico, 4, 167-182.

De Abreu, L. C. (2012). Variabilidade da frequência cardíaca como marcador funcional do desenvolvimento. Journal of Human Growth and Development, 22, 279-282. https://doi.org/10.7322/jhgd.46712

Dikker, S., Wan, L., Davidesco, I., Kaggen, L., Oostrik, M., McClintock, J., Poeppel, D. et al. (2017). Brain-to-Brain Synchrony Tracks Real-World Dynamic Group Interactions in the Classroom. Current Biology, 27, 1375-1380.

https://doi.org/10.1016/j.cub.2017.04.002

Escribano, C., \& Díaz-Morales, J. F. (2016). Are Achievement Goals Different among Morning and Evening-Type Adolescents? Personality and Individual Differences, 88, 57-61. https://doi.org/10.1016/j.paid.2015.08.032

Figueiredo de Barros, A., \& Menezes, A. (1998). Questionário factorial de personalidade de Cattell: 16 PF-5. Madrid/Lisboa: TEA/CEGOC.

Fonfría, A., Poy, R., Segarra, P., López, R., Esteller, A., Ventura, C., Moltó, J. et al. (2011). Variabilidad de la tasa cardíaca (HRV) y regulación emocional. Fòrum de recerca, 16, 903-914. http://hdl.handle.net/10234/77387

Forman-Alberti, E. B., \& Benjamin-Hinnant, J. (2016). Links between Autonomic Activity and Implicit Learning. International Journal of Psychophysiology, 110, 75-80. https://doi.org/10.1016/j.ijpsycho.2016.10.014

Geddes, M. (2017). Manual de Projetos do Arduinos. Novatec: São Paulo.

Graveline, I. M., \& Wamsley, E. J. (2017). The Impact of Sleep on Novel Concept Learning. Neurobiology of Learning and Memory, 141, 19-26.

https://doi.org/10.1016/j.nlm.2017.03.008

Griffiths, K., Quintana, D., Hermens, D., Spooner, C., Tsang, T., Clarke, S., \& Kohn, M. (2017). Sustained Attention and Heart Rate Variability in Children Andadolescents with ADHD. Biological Psychology, 124, 11-20. https://doi.org/10.1016/j.biopsycho.2017.01.004

Hasler, B., Allen, J., Sbarra, D, Bootzin, R., \& Bernert, R. (2010). Morningness-Eveningness and Depression: Preliminary Evidence for the Role of the Behavioral Activation System and Positive Affect. Psychiatry Research, 176, 166-173. https://doi.org/10.1016/j.psychres.2009.06.006

Henelius, A., Sallinen, M., Huotilainen, M., Müller, K., Virkkala, J., \& Puolamäki, K. (2014). Heart Rate Variability for Evaluating Vigilant Attention in Partial Chronic Sleep Restriction. SLEEP, 37, 1257-1267. https://doi.org/10.5665/sleep.3850

Herrera, J. Cid, N., Pinilla, C., Quezada, S., \& Santana, P. (2016). Atención selectiva, atención sostenida, inhibición y flexibilidad cognitiva en niñas y adolescentes de 12 a 14 años con TDAH predominio de falta de atención. Concepción: Universidad Católica De La Santísima.

Holzman, J., \& Bridgett, D. (2017). Heart Rate Variability Indices as Bio-Markers of 
Top-down Self-Regulatory Mechanisms: A Meta-Analytic Review. Neuroscience and Biobehavioral Reviews, 74, 233-255. https://doi.org/10.1016/j.neubiorev.2016.12.032

Horne, J. A., \& Ostberg, O. (1976). A Self-Assessment Questionnaire to Determine Morningness-Eveningness in Human Circadian Rhythms. International Journal of Chronobiology, 4, 97-110. https://cet.org/wp-content/uploads/2017/10/Horne-1976-IJC.pdf?x41674

Horzum, M. B., Önder, I., \& Beşoluk, Ş. (2014). Chronotype and Academic Achievement Namong Online Learning Students. Learning and Individual Differences, 30, 106-111. https://doi.org/10.1016/j.lindif.2013.10.017

Ingram, K. Ay, A., Kwon, S., Woods, K., Escobar, S., Gordon, Jain, K. et al. (2016). Molecular Insights into Chronotype and Time-of-Day Effects on Decision-Making. Scientific Reports, 6, 29392. https://doi.org/10.1038/srep29392

Itzek-Greulich, H., Randler, C., \& Vollmer, C. (2016). The Interaction of Chronotype and Time of Day in a Science Course: Adolescent Evening Types Learn More and Are More Motivated in the Afternoon. Learning and Individual Differences, 51, 189-198. https://doi.org/10.1016/j.lindif.2016.09.013

Katahira, K., Fujimura, T., Matsuda, Y., Okanoya, K., \& Okada, M. (2015). Individual Differences in Heart Rate Variability Are Associated with Theavoidance of Negative Emotional Events. Biological Psychology, 103, 322-331.

https://doi.org/10.1016/j.biopsycho.2014.10.007

LeDoux, J. E., \& Brown, R. (2017). A Higher-Order Theory of Emotional Consciousness. Proceedings of the National Academy of Sciences of the United States of America, 114, E2016-E2025. http://www.pnas.org/content/114/10/E2016.full.pdf https://doi.org/10.1073/pnas.1619316114

LeDoux, J. E., Phelps, L., \& Alberini, C. (2016). What We Talk about When We Talk about Emotions. Cell, 167, 1443-1445. https://doi.org/10.1016/j.cell.2016.11.029

Leocadio-Miguel, M., Mazzili, F., Lourenção, L., Peixoto, R., Alam, M. Ventura, M., Pedrazzoli, M. et al. (2017). Latitudinal Cline of Chronotype. Scientific Reports, 7, 5437. https://doi.org/10.1038/s41598-017-05797-w

Linden, D., Dunkel, C. S., \& Petrides, K. V. (2016). The General Factor of Personality (GFP) as Social Effectiveness: Review of the Literature. Personality and Individual Differences, 101, 98-105. https://doi.org/10.1016/j.paid.2016.05.020

Lonigan, C., \& Vasey, M. (2009). Negative Affectivity, Effortful Control, and Attention to Threat-Relevant Stimuli. Journal of Abnormal Child Psychology, 37, 387-399.

https://link.springer.com/article/10.1007\%2Fs10802-008-9284-y https://doi.org/10.1007/s10802-008-9284-y

Luque-Casado, A., Perales, J., Cárdenas, D., \& Sanabria, D. (2016). Heart Rate Variability and Cognitive Processing: The Autonomic Response to Task Demands. Biological Psychology, 113, 83-90. https://doi.org/10.1016/j.biopsycho.2015.11.013

MacRoberts, M. (2015). Arduino Básico (2da ed.). Novatec: São Paulo.

Markarian, S. A., Warnke, A. S., \& Pickett, S. M. (2017). Morningness-Eveningness and Social Anxiety: The Indirect Effect through Punishment Sensitivity and Experiential Avoidance. Sleep, 40, A418. https://doi.org/10.1093/sleepj/zsx050.1120

Martynhak, B., Louzada, F. M., Pedrazzoli, M., \& Fontenele-Araujo, J. (2010). Does the Chronotype Classification Need to Be Updated? Preliminary Findings. Chronobiology International, 27, 1329-1334. https://doi.org/10.3109/07420528.2010.490314

Mather, M., \& Thayer, J. (2018). How Heart Rate Variability Affects Emotion Regulation Brain Networks. Current Opinion in Behavioral Sciences, 19, 98-104. 
https://doi.org/10.1016/j.cobeha.2017.12.017

Matthews, G. (2016). Traits, Cognitive Processes and Adaptation: An Elegy for Hans Eysenck's Personality Theory. Personality and Individual Differences, 103, 61-67. https://doi.org/10.1016/j.paid.2016.04.037

Meiselman, H. (2017). Emotion Measurement: Theoretically Pure or Practical? Food Quality and Preference, 62, 374-375. https://doi.org/10.1016/j.foodqual.2017.05.011

Mogg, K., \& Bradley, B. (1999). Some Methodological Issues in Assessing Attentional Biases for Threatening Faces in Anxiety: A Replication Study Using a Modified Version of the Probe Detection Task. Behaviour Research and Therapy, 37, 595-604. https://doi.org/10.1016/S0005-7967(98)00158-2

Nobre, A. C., \& Kastner, S. (2014). The Oxford Handbook of Attention. Oxford: Oxford University Press. https://doi.org/10.1093/oxfordhb/9780199675111.001.0001

Ohyama, T., Kaga, Y., Goto, Y., Aoyagi, K., Ishii, S., Kanemura, H., Aihara, M. et al. (2016). Developmental Changes in Autonomic Emotional Response during an Executive Functional Task: A Pupillometric Study during Wisconsin Card Sorting Test. Brain \& Development, 39, 187-195. https://doi.org/10.1016/j.braindev.2016.10.002

Onley, A., Risko, E., D'mello, S., \& Graesser, A. (2015). Attention in Educational Contexts: The Role of the Learning Task in Guiding Attention. In J. Fawcett, E. Risko, \& A. Kingstone (Eds.), The Handbook of Attention (pp. 623-641). London: MIT Press.

Ortega, A., Ramírez, E., Colmenero, J., \& García-Viedma, M. (2012). Negative Affect, Decision Making and Attentional Networks. Journal of Attention Disorders, 21, 247-253. https://doi.org/10.1177/1087054712465336

Pacheco-Unguetti, A., Acosta, A., Callejas, A., \& Lupiáñez, J. (2010). Attention and Anxiety: Different Attentional Functioning under State and Trait Anxiety. Psychological Science, 21, 298-304. https://doi.org/10.1177/0956797609359624

Peers, P. V., \& Lawrence, A. D. (2009). Attentional Control of Emotional Distraction in Rapid Serial Visual Presentation. Emotion, 9, 140-145.

Pessoa, L. (2018). Understanding Emotion with Brain Networks. Current Opinion in Behavioral Sciences, 19, 19-25. https://doi.org/10.1016/j.cobeha.2017.09.005

Pincus, S. M. (1991). Approximate Entropy as a Measure of System Complexity. Proceedings of the National Academy of Sciences of the United States of America, 88, 2297-2301. https://doi.org/10.1073/pnas.88.6.2297

Porges, S. W. (1995). Orienting in a Defensive World: Mammalian Modifications of Our Evolutionary Heritage: A Polyvagal Theory. Psychophysiology, 32, 301-318. https://doi.org/10.1111/j.1469-8986.1995.tb01213.x

Porges, S. W. (2001). The Polyvagal Theory: Phylogenetic Substrates of a Social Nervous System. International Journal of Psychophysiology, 42, 123-146. https://doi.org/10.1016/S0167-8760(01)00162-3

Porges, S. W. (2007). The Polyvagal Perspective. Biological Psychology, 74, 116-143. https://doi.org/10.1016/j.biopsycho.2006.06.009

Purnamaningsih, E. (2017). Personality and Emotion Regulation Strategies. International Journal of Psychiatry Research, 10, 53-60. https://doi.org/10.21500/20112084.2040

Quintana, D., Guastella, A., Outhred, T., Hickie, I., \& Kemp, A. (2012). Heart Rate Variability Is Associated with Emotion Recognition: Direct Evidence for a Relationship between the Autonomic Nervous System and Social Cognition. International Journal of Psychophysiology, 86, 168-172. https://doi.org/10.1016/j.ijpsycho.2012.08.012

Ramírez, R., Ortega, A., \& Reyes, G. (2015). Anxiety, Attention, and Decision-Making: 
The Moderating Role of Heart Rate Variability. International Journal of Psychophysiology, 490, 490-496. https://doi.org/10.1016/j.ijpsycho.2015.10.007

Randler, C., \& Rahafar, A. (2017). Latitude Affects Morningness-Eveningness: Evidence for the Environment Hypothesis Based on a Systematic Review. Scientific Reports, 7, 39976. https://doi.org/10.1038/srep39976

Revelle, W. (2016). Hans Eysenck: Personality Theorist. Personality and Individual Differences, 103, 32-39. https://doi.org/10.1016/j.paid.2016.04.007

Rico, D., Alzate, M., \& Sabucedo, J. (2017). El papel de la identidad, la eficacia y las emociones positivas en las acciones colectivas de resistencia pacífica en contextos violentos. Revista Latinoamericana de Psicología, 49, 28-35. https://doi.org/10.1016/j.rlp.2015.09.013

Robe, A., Dobrean, A., Cristea, I. A., Păsărelu, C. R., \& Predescu, E. (2019). Attention-Deficit/Hyperactivity Disorder and Task-Related Heart Rate Variability: A Systematic Review and Meta-Analysis. Neuroscience and Biobehavioral Reviews, 99, 11-22. https://doi.org/10.1016/j.neubiorev.2019.01.022

Roenneberg, T., Wirz-Justice, A., \& Merrow, M. (2003). Life between Clocks: Daily Temporal Patterns of Human Chronotypes. Journal of Biological Rhythms, 18, 80-90. https://doi.org/10.1177/0748730402239679

Roeser, K., Obergfell, F., Meule, A., Vögele, C., Schlarb, A., \& Kübler, A. (2012). Of larks and Hearts-Morningness/Eveningness, Heart Rate Variability and Cardiovascular Stress Response at Different Times of Day. Physiology \& Behavior, 106, 151-157. https://doi.org/10.1016/j.physbeh.2012.01.023

Rohr, C., Arora, A., Cho, I., Katlariwala, P., Dimond, D., Dewey, D., \& Bray, S. (2018). Functional Network Integration and Attention Skills in Young Children. Developmental Cognitive Neuroscience, 30, 200-211. https://doi.org/10.1016/j.dcn.2018.03.007

Sanchis, L., Prat, P., \& Sitges, M. (2016). Imagen cardiovascular en la sala de electrofisiología. Revista Española de Cardiología, 69, 595-605. https://doi.org/10.1016/j.recesp.2016.01.028

Scott-Parker, B. (2017). Emotions, Behaviour, and the Adolescent Driver: A Literature Review. Transportation Research Part F, 50, 1-37. https://doi.org/10.1016/j.trf.2017.06.019

Serrano-Trejo, M., Leija-Alva, G., Aguilera-Sosa, V., \& Rodríguez-Choreño, J. (2012). Relación entre el incremento de la variabilidad de la frecuencia cardiaca y la regulación del comportamiento alimentario en niños con obesidad. Revisión teórica. Revista Mexicana de Investigación en Psicología, 4, 34-44.

https://www.medigraphic.com/pdfs/revmexinvpsi/mip-2012/mipM121d.pdf

Shaffer, F., \& Venner, J. (2013). Heart Rate Variability Anatomy and Physiology. Biofeedback, 41, 13-25. https://doi.org/10.5298/1081-5937-41.1.05

Shaffer, F., McCraty, R., \& Zerr, C. (2014). A Healthy Heart Is Not a Metronome: An Integrative Review of the Heart's Anatomy and Heart Rate Variability. Frontiers in Psychology, 5, 1040. https://doi.org/10.3389/fpsyg.2014.01040

Tarvainen, M. P., Niskanen, J. P., Lipponen, J. A., Ranta-aho, P. O., \& Karjalainen, P. A. (2014). Kubios HRV-Heart Rate Variability Analysis Software. Computer Methods and Programs in Biomedicine, 113, 210-220. https://doi.org/10.1016/j.cmpb.2013.07.024

Thayer, J. F., \& Lane, R. D. (2000). A Model of Neurovisceral Integration in Emotion Regulation and Dysregulation. Journal of Affective Disorders, 61, 201-216. https://doi.org/10.1016/S0165-0327(00)00338-4 
Thayer, J. F., Hansen, A. L., Saus-Rose, E., \& Johnsen, B. H. (2009). Heart Rate Variability, Prefrontal Neural Function, and Cognitive Performance: The Neurovisceral Integration Perspective on Self-Regulation, Adaptation, and Health. Annals of Behavioral Medicine, 37, 141-153. https://doi.org/10.1007/s12160-009-9101-z

Tomelin, M. (2002). Sistema de apuração dos dezesseis fatores de personalidade. Blumenau, Brasil: Universidade Regional de Blumenau.

Tonetti, L., Natale, V., \& Randler, C. (2015). Association between Circadian Preference and Academic Achievement: A Systematic Review and Meta-Analysis. Chronobiology International, 32, 792-801. https://doi.org/10.3109/07420528.2015.1049271

Touitou, Y, Touitou, D., \& Reinberg, A. (2017). Disruption of Adolescents' Circadian Clock: The Vicious Circle of Media Use, Exposure to Light at Night, Sleep Loss and Risk Behaviors. Journal of Physiology-Paris, 110, 467-479.

Vollmer, C., Pötsch, F., \& Randler, C. (2013). Morningness Is Associated with Better Gradings and Higher Attention in Class. Learning and Individual Differences, 27, 167-173. https://doi.org/10.1016/j.lindif.2013.09.001

Wilson, K., \& Korn, J. H. (2007). Attention During Lectures: Beyond Ten Minutes. Teaching of Psychology, 34, 84-89.

Yentes, J., Hunt, N., Schmid, K., Kaipust, J., McGrath, D., \& Stergiou, N. (2013). The Appropriate Use of Approximate Entropy and Sample Entropy with Short Data Sets. Annals of Biomedical Engineering, 41, 349-365.

https://doi.org/10.1007/s10439-012-0668-3

Yoo, K., Rosenberg, M., Hsu, W., Zhang, S., Li, C., Scheinost, D., Constable, T., \& Chun, M. (2018). Connectome-Based Predictive Modeling of Attention: Comparing Different Functional Connectivity Features and Prediction Methods across Datasets. NeuroImage, 167, 11-22. https://doi.org/10.1016/j.neuroimage.2017.11.010

Zanon, C., Roat, M., Cerentini, J., \& Hutz, C. (2013). Desenvolvimento e validação de uma escala de afetos positivos e negativos. Bragança Paulista, 18, 193-202. https://doi.org/10.1590/S1413-82712013000200003 